\title{
O PROFESSOR E O CHAMADO A "SER HOLÍSTICO”
}

\author{
Prof. Dr. Gabriel César Dias Lopes, PhD
}

\section{RESUMO}

Este artigo reporta o desafio iminente de ser um professor holístico dentro de um contexto onde as relações são nítida e notadamente marcadas pelo Capitalismo em um jogo de contrários onde discurso e idealismo se confundem à prática e onde a cada dia parece ainda mais impossível um diálogo de fazeres. Discute-se aqui dentro da perspectiva histórica e como alternativa para a resolução do impasse o trabalho enquanto uma dupla relação de transformação simbiótica e significativa entre o homem e a natureza, aproximando-os e tornando-os coesos. Utilizou-se aqui uma pesquisa bibliográfica com autores que caracterizam o trabalho do professor no contexto histórico e com filósofos que caracterizam a postura do homem enquanto ser holístico mesmo diante de um trabalho deveras massificante e desumanizador.

Palavras-Chave: Professor, Holístico, Trabalho.

\section{ABSTRACT}

This article reports the imminent challenge of being inside a holistic professor of a context where the relations clear and notadamente are notadamente marked by the Capitalism in a contrary game where speech and idealismo if confuse to the practical one and where to each day it still more seems impossible a dialogue to make. The work is argued here inside of the historical perspective as alternative for the resolution of the impasse while a double relation of simbiótica and significant transformation between the man and the nature, approaching them and becoming them coesos. A bibliographical research with authors who characterize the work of the professor in the historical context and with philosophers was used here who characterize the position of the man while to be holistic exactly ahead of a indeed massificante and desumanizador work. 
Word-Key: Teacher, Holistic, Work.

* Gabriel César Dias Lopes é Ph.D é Graduado em: Teologia, Direito, Administração e Recursos Humanos, MBA em Marketing e Gestão Estratégica, Pós-Graduado em Psicanálise, Coordenador do Curso de Pós Graduação Lato Sensu em Psicanálise Clinica da FABIC, Mestre em Educação, Mestre em Administração, Doutor em Educação e um Ph.D em Psicanálise. Membro da International Special Court of Arbitration and Human Rights - Registro: ISCAHRGCDL-17/11n2016, Membro da Comissão Científica da Olympus Intellectual Center, Atenas (Grecia), Presidente da LUI - Logos University International. 


\section{INTRODUÇÃO}

A realidade da educação no Brasil é dicotômica, de um lado se aponta para a formação profissional direcionada ao mercado de trabalho e de outro exige-se uma formação mais humanista, voltada à formação integral e aos pressupostos do holismo.

O homem contemporâneo, face a complexidade e instabilidade do mundo, tem paulatinamente se tornado um ser solitário, desconectado consigo mesmo, com o outro e com a natureza. Vem perdendo a conexão com tudo o que é vivo, com o mais íntimo de seu ser, não olha, nem escuta, não toca e ignora o outro, tendo dificuldade de interagir socialmente.

Atravessa um longo processo de degradação dos instintos, sente-se incapaz de relacionar-se com o prazer, com o amor e com a alegria de viver, agride a si mesmo e ao meioambiente como se não fizesse parte do mesmo e encontra-se desconectado com a função da vida, ocasionando-lhe fragilidade física e psicoemocional.

O holismo é aqui entendido justamente com a conexão, ou melhor dizendo nesse caso, a reconexão do homem consigo mesmo e com seu entorno, restaurando suas possibilidades de plena convivência com o meio a que pertence. Através do princípio biocêntrico fomenta a relação íntima e cuidadosa do homem consigo mesmo, com o outro e com o universo

Fruto de uma sociedade que através de suas instituições políticas, educativas e religiosas supervaloriza, os bens materiais, a posição social, o dinheiro em detrimento da cultura, da natureza, da simplicidade e da espiritualidade da vida, havendo, portanto, um predomínio acentuado da razão sobre o orgânico, esse homem sente-se perdido e não sabe o que fazer diante da incerteza e das múltiplas verdades dos fenômenos atuais, com prejuízos para o seu desenvolvimento e crescimento pessoal.

Nesse contexto, a educação vem sido constantemente desafiada a participar da transição desse homem, a partir do próprio professor e seguindo para o aluno e todo seu entorno, para tornarem-se seres conectados com o Todo, mesmo diante da grande instabilidade do mundo, em meio a desordens de cunhos existenciais, políticos e filosóficos que principalmente nos pós Segunda Guerra Mundial, pôs em xeque e evidenciou a crise da cultura ocidental.

Esse artigo, discute o contexto do professor brasileiro na atualidade, buscando caracteriza-lo em seus desafios frente ao Capitalismo evidente no período pós-64 e diante das demandas do mundo que o convida a ser um professor holístico, na antítese desse mesmo Capitalismo. 
Para tanto, alguns teóricos como Morin, Maturana, Goleman são discutidos na reflexão do ser holístico e outros como Romanelli, Freitas e Drucker contextualizam o professor enquanto sujeito e agente histórico, repleto de exigências no seu entorno e principalmente no que diz respeito a sua formação e atuação.

\section{BRASIL PÓS 1964, CAPITALISMO E O PROFESSOR}

Conforme Romanelli (2000) há uma relação imbrincada entre a educação e o desenvolvimento capitalista no Brasil. Considerando que os modelos educacionais vigentes no país sempre acompanharam os interesses oficiais voltados à política econômica e os projetos de acumulação de riquezas, Romanelli examina as diversas fases da história da educação ao mesmo tempo em que investiga o desenrolar dos efeitos daqueles projetos na sociedade assim, se o Brasil encontrava-se atrasado no contexto internacional em termos de industrialização, essa conclusão influencia os modelos educacionais propostos (às vezes a partir do Brasil, outros oriundos dos Estados Unidos) e aqui executados.

Observa-se expansão industrial brasileira foi acompanhada de perto por formas précapitalistas de produção típicas do campo e presentes no cotidiano do país. A partir do governo de Juscelino Kubitschek, com seu plano de metas, e posteriormente, ao longo do regime militar, Industrialização entra em um ritmo mais acelerado. O Brasil buscava, então, em um contexto de crescimento capitalista dos países desenvolvidos, se recuperar de um atraso histórico, embora sem condições reais de êxito.

A partir de 1964 estimula-se uma industrialização, ainda dependente dos países centrais, enquanto o governo militar mantém sua política autoritária, que se estende às instituições e empresas, onde os trabalhadores experimentam a repressão patronal e o controle despótico sobre sua vida e labor. Essa dependência brasileira provocou uma crise recessiva na economia entre final dos anos 1970 e início dos anos 1980. Era o fim do modelo, uma crise que transbordaria para outras esferas da vida do país, enfim era o fim do "milagre brasileiro'.

Assim, a rearticulação das empresas por maior competividade afetou também o padrão de gestão de mão-de-obra que havia até então no país, abrindo espaço para a introdução de novos processos produtivos a partir da década de 80, e com maior vigor nos anos 1990, acompanhados de duas particularidades: i) A abertura da economia, com a redução de alíquotas de importação, que vem exigindo mudanças organizacionais para enfrentar a competitividade; 
e ii) a política recessiva colocada em prática pelo governo no início da década, a fim de combater o processo crônico de inflação no país. (DRUCKER, 2002, p.81).

O movimento social ganhou força e foi se estabelecendo mesmo em espaços improváveis na época de maior furor da ditadura. Tem início uma luta histórica pela redemocratização no país marcada pela mobilização operária e por outros movimentos urbanos que demonstravam que a luta era contra o modelo e a reação era a resposta às humilhações sofridas no cotidiano fabril. Assim, conforme (FREITAS 2013) a luta dos trabalhadores busca, no limite e junto com outros sujeitos sociais, o fim da política autoritária e recessiva para o país, e, entre eles, o fim do controle patronal autoritário no interior das empresas.

Por outro lado, a estratégia das empresas por ampliar a competitividade leva em conta o ambiente político. A entrada de uma maior automatização no processo produtivo é, então, acompanhada por padrões de gestão que necessitavam "de uma força de trabalho mais comprometida com os objetivos gerenciais" (FREITAS,2013 P.140). Isto é: o desejo do trabalhador em se manter trabalhando sob as condições impostas pelas empresas sem, contudo, abrir mão de um controle rigoroso sobre a produção e sobre os trabalhadores.

A essa altura, as empresas, ao adotar novas formas de gerenciamento da exploração dos trabalhadores, beneficiavam-se de alterações em leis trabalhistas promovidas ao longo do regime militar (como a substituição paulatina da estabilidade pelo Fundo de Garantia por Tempo de Serviço e a lei do trabalho temporário por empresas prestadoras de serviços, que autoriza a terceirização pessoal), que facilitavam a rotatividade de mão-de-obra.

Drucker (2002) lembra a que a insistência do discurso em torno da qualidade total / competitividade, a terceirização e a manutenção de um regime autoritário de trabalho no interior da planta fabril, em desfavor dos trabalhadores é uma típica condita empresária. Segundo Drucker (2002), a década de 80 e, principalmente, a de 90, testemunharam um processo de “desfordização, constituindo uma nova cultura, na qual se combinam elementos do fordismo com o de novas formas de produção.

Esse movimento gerencial provocou alterações nas relações de trabalho: além dos efeitos tradicionais da terceirização - queda do valor do salarial e vínculos frágeis e de pouca duração -, foram reduzidos o número de trabalhadores empregados e os direitos trabalhistas. Nesse período em que são adotadas as novidades gerenciais, os indicadores da produção petroquímica apontam queda no curso do trabalho e aumento de produtividade.

Como suporte legal a facilitar esses novos processos produtivos e modelos gerenciais do final do século $\mathrm{XX}$, sob a égide dos governos neoliberais, o país passa a ter regras e 
orientações na área de qualidade (DRUCKER, 2002) além de novidades em leis trabalhistas e previdenciárias, que ampliaram a degradação das condições e dos contratos de trabalho (FREITAS, 2013).

O objetivo das novas leis, segundo o discurso oficial, seria a promoção da competitividade, através da redução do gasto capitalista na remuneração da força de trabalho, por meio da extinção, parcial ou integral, de direitos dos trabalhadores. Repete-se a conduta do regime militar (1964/1985), mas em um novo cenário, pois ao longo do governo Cardoso houve um aprofundamento da precarização do trabalho então em andamento.

No período 1995/2002, as reformas trabalhistas passaram a exigir a participação sindical na formalização de contratos e condições de trabalho em bases precárias. Além do suporte legal ao capital o Estado, através da nova ordem jurídica, oferece a "oportunidade" política não só de quebrar resistências sindicais, mas de tornar os sindicatos cúmplices da fragilização do trabalho.

Esse novo parâmetro da lei não nasce do Estado, mas do movimento sindical. O governo Cardoso propôs normas cujos teores já haviam sido discutidos como objetos de negociações coletivas pontuais e localizadas, em que estava presente a possibilidade real de redução de direitos, a partir de reivindicações de sindicatos de trabalhadores ao patronato. Para esse fenômeno de evidente peleguismo, pesou significativamente a participação da Força Sindical, central sindical criada na década de 90 com o objetivo explícito de se contrapor à ação sindical contestadora da CUT. (FREITAS, 2013).

A força sindical e seu "sindicalismo de resultados" priorizou a manutenção de empregos, mesmo que de má qualidade, em relação à conquista de direitos - conduta que Soria e Girard (1996) denominam de "flexibilidade defensiva/liberal" e que, na teorização proposta por Mészáros, seria o extremo do que chama de "entrincheiramento defensivo". (FREITAS, 2013).

Articulados, o governo Fernando Henrique Cardoso e a Força Sindical atuam juntos no combate ao sindicalismo da CUT, cuja história é marcada pelas tentativas de constranger o patronato na esperança de conquistas de melhores condições e contratos de trabalho. As novidades legislativas, portanto, têm eficácia condicionada à aceitação dos sindicatos, isto é, a possibilidade de precarização de direitos individuais e de degradação do próprio ser coletivo, desde que consentida pelas entidades representativas dos trabalhadores. (FREITAS, 2013).

Enquanto isso a social - democracia europeia convocou o movimento sindical a participar do pacto de sustentação do welfarestate, e depois, e não apenas da Europa, para um 
"compromisso" do trabalhador a formas flexíveis de produção, o governo social - democrata brasileiro, dirigido pelo PSDB, propôs medidas que implicariam na piora das condições e contratos de trabalho desde que os próprios sindicatos de trabalhadores concordassem. Tratase de uma situação que foi se articulando e se concretizando ao longo do governo Cardoso. (FREITAS, 2013).

Para o então presidente Fernando Henrique Cardoso (2003), a ação dos sindicalistas foi fundamental para atrasar a introdução de políticas neoliberais no Brasil em cerca de uma década, porém essa mesma ação é prejudicada com o fim dos altos índices inflacionários a partir de 1994 e dos anos seguintes, exatamente no Governo Cardoso. Isto porque a luta sindical, que se pautava excessivamente em reivindicações salariais em um cotidiano de alta inflação, sofreu contraditoriamente, um esvaziamento de "bandeiras" econômicas. Esse fator e mais os efeitos do desemprego, da terceirização e das reestruturações produtivas, resultam em redução da mobilização dos trabalhadores em assembleias e em atividades sindicais.

Um cenário que acabou por fortalecer a postura neoliberal em negociações coletivas, em detrimento a direitos trabalhistas e previdenciários. Um prejuízo que não se limitou aos trabalhadores de categorias organizadas, como metalúrgicos, petroquímicos e bancários, mas que também se estendeu àqueles que tradicionalmente se localizam em situações de desvantagens, como os trabalhadores de categorias inorganizadas e os informais. (FREITAS, 2013).

É assim, na informalidade que se identificam os meios mais violentos e radicais de exploração do trabalho praticados pelo capital, sem qualquer respeito à legalidade. A quantidade de postos de trabalho informais manteve-se alta no final do século XX e no início do XXI, mesmo com o aumento da formalidade percebido a partir de 2007. O universo do informal é amplo e não afeito as negociações coletivas, por se situar em patamar inferior ao mínimo legal. Mesmo assim, o modelo do contrato formal, e com ele o fordismo, se constitui como paradigma aos meios informais de exploração do trabalho não necessariamente respeitam formalidades legais para o registro do vínculo trabalhista.

Esse rápido panorama, aqui foi aqui descrito apenas para realçar o impacto do modo de produção e da forma como ele se organiza interfere diretamente em condições de vida objetiva. O exercício da atividade educadora é marcado atualmente pela constante sujeição do professor a ritmos acelerados de trabalho, a sobrecargas laborativas, a riscos à saúde física e mental, além da degradação salarial e deterioração dos direitos individuais. Assim sendo como tornar-se um 
professor holístico, quando sua vida material e emocional é marcadamente repleta de mecanismos de exploração e degradação?

\section{REALIDADE DO PROFESSOR E OS PRESSUPOSTOS DA FORMAÇÃO HOLÍSTICA}

De acordo com Nóvoa (1992) atualmente todos os pressupostos de formação profissional na área de educação devem estimular uma perspectiva crítico-reflexiva, que forneça aos professores os meios de um pensamento autônomo e que facilite as dinâmicas de auto formação participada (Nóvoa, 1992, p.25)

Nóvoa também chama atenção ao fato de que se exige do professor um preparo para resolver os problemas sociais que a sociedade não resolve, assim, a formação docente talvez seja um dos maiores desafios da educação como um todo atualmente A crítica se dá dentro de uma escola que transita entre resquícios de uma formação tradicional totalmente voltado para o cognitivismo para uma formação democrática que não tem um consenso entre modelos e vertentes. É nas questões que envolvem a formação de professores para o ensino básico que se destaca a reflexão da prática docente como um dos requisitos básicos para a formação do professor reflexivo e para a educação continuada do mesmo.

O professor técnico reprodutor de conhecimentos e um mero executor de tarefas preestabelecidas foi substituído por um professor holístico, contextualizado. Naquela perspectiva, a formação de professores tinha como preocupação a instrumentalização técnica, concebida como um fim em si mesma e considerada como um elenco de procedimentos a serem dominados, para serem "aplicados" em situações de ensino-aprendizagem, na maioria das vezes, de forma descontextualizada.

Atualmente a questão da formação de professores e da profissão docente tem sido central nas propostas de reformas educacionais, na tentativa de romper com o modelo da racionalidade técnica e com a concepção do ensino como um processo técnico. A exigência por um professor reflexivo, que busque superar a relação linear e mecânica entre o conhecimento científico e a prática na sala de aula, introduz um novo conceito de formação de professores, que deve romper com as práticas exercidas até o momento.

O professor deve tornar-se um profissional ativo e crítico no verdadeiro processo de inovação e mudança, a partir do seu próprio contexto, Com isso, "a formação pretende obter um profissional que deve ser, ao mesmo tempo, agente da mudança, individual e coletivamente, 
e embora seja importante saber o que deve fazer e como, também é importante saber por que deve fazê-lo" (IMBERNÓN, 2004, p. 38).

Ao se assumirem como produtores de seu próprio fazer pedagógico o professor assume a responsabilidade de mudar o contexto em que está inserido e isso por vezes foge ao seu alcance. Mudar a si mesmo é um processo árduo, o que dizer então da tarefa de mudar a escola, mudar as relações da comunidade escolar, mudar o currículo, mudar o entorno social. Assim, as escolas não podem mudar sem o comprometimento dos professores; e estes não podem mudar sem a transformação das instituições de formação em que trabalham e se formam. É preciso, de acordo com Nóvoa (1992), trabalhar no sentido da diversificação dos modelos e das práticas de formação, instituindo novas relações dos professores com o saber pedagógico e científico. Filosoficamente o ideal.

Desta forma, Nóvoa (1992:.25), propõe a formação de professores numa perspectiva que denomina crítico-reflexiva, que "forneça aos professores os meios de um pensamento autônomo e que facilite as dinâmicas de autoformação participada, com vista à construção de uma identidade profissional". Diante disso, considera três aspectos na formação docente: produzir a vida do professor (desenvolvimento pessoal), produzir a profissão docente (desenvolvimento profissional) e produzir a escola (desenvolvimento organizacional).

O professor holístico, vai além do modelo tomado por Nóvoa, pois o novo paradigma de mundo e de ciência exige mais e mais do profissional. A construção e reconstrução do mundo exige que o modelo cartesiano seja deixado de lado e que a educação ao se tornar eixo norteador possibilite diálogos amplos, globais que possibilitem ao sujeito uma abertura para a construção de um mundo mais humano, renovado, uma sociedade mais justa, fraterna e estabilizada , apesar de em movimento. Aqui o ser professor toma uma conotação diferenciada, pois o saber científico sozinho há muito não resolve os conflitos. Exige-se muito mais desse profissional.

(...) Ser professor requer saberes e conhecimentos científicos, pedagógicos, educacionais, sensibilidade, indagação teórica e criatividade para encarar as situações ambíguas, incertas, conflituosas e, por vezes, violentas, presentes nos contextos escolares e não escolares. É da natureza da atividade docente proceder à mediação reflexiva e crítica entre as transformações sociais concretas e a formação humana dos alunos, questionando os modos de pensar, sentir, agir e de produzir e distribuir conhecimentos. (SEVERINO e PIMENTA apud PIMENTA e ANASTASIOU, 2005).

Assim, a formação autônoma do professor faz toda a diferença diante das situações, nas quais, ele deve decidir o que, o como, o quando e qual atitude tomar, visando a mudança e a qualidade da educação. Desta forma, é interessante compreender que os processos de formação apresentam um caráter dinâmico, instável, incerto e ambíguo, onde a homogeneização e as estratégias normativas de ação e intervenção cedem lugar à necessidade e atitude reflexiva em 
que a capacidade de dialogar com as situações e de diagnosticá-las sustentam ações construtivas no processo.

Considerando a importância da reflexão na trajetória de formação e atuação docente é que esboçamos eixos norteadores dos processos formativos, sabendo que a formação reflexiva envolve tanto atitudes, saberes como competências que proporcionem condições para que os profissionais desempenhem um papel ativo na elaboração de objetivos, estratégias, avaliações, enfim, práticas que emanem da cabeça e das mãos dos professores, por meio de um ensino reflexivo que instigue nos mesmos o desejo de aprender e de ensinar sempre levando em consideração as responsabilidades do professor em sua prática, com a clareza de que se situa, estabelecendo parâmetros de ações contextualizadas e críticas, problematizando-as permanentemente.

Coloca-se assim em evidência a indiscutível contribuição da perspectiva da reflexão na formação inicial de professores bem como no exercício da docência. A reflexividade se insere como um dos elementos de formação inicial e/ou continuada, compreendida como um processo articulado de ação-reflexão-ação, ou seja, um processo que começa com a prática, posteriormente com a reflexão e se traduz em ação concreta, imprimindo uma nova reflexão e um novo fazer diferenciado.

Do ponto de vista da formação holística isso representa que a educação nesse eixo vai priorizando a formação do indivíduo seja ele professor ou aluno na sua globalidade e inteireza acatando sua experiência transdisciplinar e proporcionando o desenvolvimento da compreensão e vivência no mais alto teor dos sentidos.

Erigir a vida de professor implica proporcionar aos professores espaços de interação entre as dimensões pessoais e profissionais, ou seja, permitindo aos professores que, ao se apropriarem de conteúdos de sua formação, possam transpor esses conhecimentos para suas práticas e para suas experiências compartilhadas. A experiência como lugar de produção do saber e de aprendizagem, passa a considerar que o professor constrói o seu saber ativamente ao longo da vida, por isso, "é importante investir a pessoa e dar um estatuto ao saber da experiência".

Conceber a profissão docente se dá por meio de uma formação que promove a preparação de professores reflexivos, que assumem a responsabilidade por sua auto formação e que interagem na implementação das políticas públicas e educacionais. É preciso investir nos saberes de que o professor é possuidor, trabalhando-os do ponto de vista teórico e conceitual. Os problemas enfrentados pelos professores na prática profissional, ocorrem em situações 
problemáticas que obrigam a tomada de decisões num terreno de grande complexidade, incerteza, singularidade, conflitos e valores. Não é simplesmente um problema instrumental, às vezes é institucional e vai além do que ele pode no momento.

Conceber a escola como um espaço de formação e atuação implica a formação como um processo permanente, integrado no dia-a-dia dos professores e da escola. Nessa perspectiva, ser professor ou tornar-se professor perpassa caminhos incertos, ambíguos e desconhecidos, aonde cada um vai construindo sua maneira de ser e estar na profissão.

O ser holístico aqui, requer muito do professor. Não é à toa que pesquisas feitas em muitos locais do país demonstram os índices enormes de faltas no trabalho, desistência da profissão por inúmeros fatores. Existe um mal-estar que perpassa as relações na escola e os profissionais parecem estar a todo momento à espera de algo indizível que pode vir a acontecer. De acordo com Libâneo, (2000, p. 28) uma nova escola exige dos docentes novas atitudes, destacadas a seguir:

1. Assumir o ensino como mediação: aprendizagem ativa do aluno com a ajuda pedagógica do professor.

2. Modificar a idéia de uma escola e de uma prática pluridisciplinar para uma escola e uma prática interdisciplinar.

3. Conhecer estratégias do ensinar a pensar, ensinar a aprender a aprender.

4. Persistir no empenho de auxiliar os alunos a buscarem uma perspectiva crítica dos conteúdos, a se habituarem a apreender as realidades enfocadas nos conteúdos escolares de forma crítico-reflexiva.

5. Assumir o trabalho de sala de aula como um processo comunicacional e desenvolver capacidade comunicativa.

6. Reconhecer o impacto das novas tecnologias da comunicação e informação na sala de aula (televisão, vídeo, games, computador, internet, CD-Rom etc.).

7. Atender à diversidade cultural e respeitar as diferenças no contexto da escola e da sala de aula.

8. Investir na atualização científica, técnica e cultural, como ingredientes do processo de formação continuada.

9. Integrar no exercício da docência a dimensão afetiva.

10. Desenvolver comportamento ético e saber orientar os alunos em valores e atitudes em relação à vida, ao ambiente, às relações humanas, a si próprios. (LIBÂNEO,2000, p. 28)

O que fica claro diante do exposto é que se espera muito do professor. Seu papel nos últimos anos foi extrapolando a mediação do processo de conhecimento do aluno, ampliando a missão do profissional para além da sala de aula, a fim de garantir uma articulação entre a escola e a comunidade. O professor, além de ensinar, deve participar da gestão e do planejamento escolares, o que significa uma dedicação mais ampla, a qual se estende às famílias e à comunidade.

A ideia da interdisciplinaridade e da pluridisciplinaridade solicitada ao professor holístico requer do professor a poli e multidisciplinaridade em sua formação, passando ele a 
atuar assim em funções que excedem suas forças e formação. Um exemplo disso é a forma forçosa com a qual as tecnologias de informação foram inseridas na escola, forçando os professores a buscarem qualificação por si próprios, sem que a escola disponibilizasse esse acesso.

Embora o sucesso da educação dependa do perfil do professor, a escola enquanto instituição e as políticas públicas que aí estão não fornecem os meios pedagógicos necessários à realização das tarefas, cada vez mais complexas que é cuidar dessa integralidade do ser humano. Assim os professores são forçados a procurar as vezes de forma solitária e sem direcionamento formas de requalificação que se traduzem em aumento não reconhecido e não remunerado da jornada de trabalho (TEIXEIRA,2001; BARRETO E LEHER, 2003; OLIVEIRA, 2003).

Segundo o Novo Dicionário da Língua Portuguesa, de Aurélio Buarque de Holanda Ferreira, educação é: "processo de desenvolvimento da capacidade física, intelectual ou moral da criança e do ser humano em geral, visando à sua melhor integração individual e social". O processo de educação começa com a família, quando os pais ensinam a seus filhos o que julgam ser certo, como devem se comportar, a respeitar as outras pessoas. Ou seja, é o início da formação da criança, que aos poucos vai sendo preparada para a vida individual e em sociedade.

Num segundo momento, entra em cena a escola. Tem início a etapa da instrução da criança, onde ela vai adquirir conhecimentos referentes a áreas do saber específicas: Língua Portuguesa, Matemática, Geografia, História, entre outras. Mas o papel da escola na formação do indivíduo não fica restrito a esse tipo de informação. De certa forma, a escola vai dar continuidade ao processo que foi iniciado pela família, educando a criança e o adolescente também para a vida, através da disciplina, das responsabilidades, do estímulo ao exercício da cidadania.

Até aí tudo normal. O problema é quando essa responsabilidade da família passa para a escola e consequentemente para o professor. Realmente a carga fica difícil de suportar. Sobrecarregado e reificado o professor vive em meio a emoções perturbadoras e relacionamentos interpessoais tóxicos que também são identificados como fatores de risco que favorecem o desenvolvimento de algumas doenças

A reificação do professor é assim um problema contemporâneo Ocorre então que aqueles professores dedicados e envolvidos com seu trabalho, ao se depararem com a distância entre o ideal e o possível de realizar diante dos enfrentamentos diários no chão da escola real, 
perante as contradições e desafios cotidianos, foram tomados por uma crise de identidade profissional que por vezes descambou para uma crise pessoal, uma vez que a vida profissional representa muito para a construção da identidade pessoal do ser humano. $\mathrm{O}$ desencanto que se tomou com a profissão comprometeu o então ressurgente professor holístico.

Fritjof Capra (1997) chama a atenção para esse fato quando coloca o seguinte:

Quando as estruturas sociais e padrões de comportamento tornam-se tão rígidos que a sociedade não pode mais adaptar-se a situações cambiantes, ela é incapaz de levar avante o processo criativo de evolução cultural. Entra em colapso e, finalmente, desintegra-se. (CAPRA,1997)

A desintegração da educação e das instituições escolares é uma amostra de uma sociedade doente e em pleno caos no descontrole do desenvolvimento. Pensa-se em progresso quando na verdade há o regresso daquilo que nos torna humanos. Estamos em plena contramão da humanidade, quando pensamos avançar histórica, cientifica e filosoficamente. Confundimos todo o avanço tecnológico com o avanço do senso de humanidade. Isso não é real.

De acordo com CAPRA, (1997):

O excessivo crescimento tecnológico criou um meio ambiente no qual a vida se tornou física e mentalmente doentia. Ar poluído, ruídos irritantes, congestionamento de tráfego, poluentes químicos, riscos de radiação e muitas outras fontes de estresse físico e psicológico passaram a fazer parte da vida cotidiana da maioria das pessoas. Esses múltiplos riscos para a saúde não são apenas subprodutos casuais do progresso tecnológico; são características integrantes de um sistema econômico obcecado com o crescimento e a expansão, e que continua a intensificar sua alta tecnologia numa tentativa de aumentar a produtividade.”. (CAPRA,1997)

Segundo esse autor nossa obsessão pelo dinheiro é que nos levará ao caos. Sobre isso afirma:

\begin{abstract}
Nossa obsessão pelo crescimento econômico e pelo sistema de valores que lhe é subjacente criou um meio ambiente físico e mental no qual a vida se tornou extremamente insalubre. Talvez o aspecto mais trágico desse dilema social seja o fato de que os perigos à saúde criados pelo sistema econômico são causados não só pelo processo de produção, mas pelo consumo de muitos dos artigos que são produzidos e promovidos por campanhas maciças de publicidade para alimentar a expansão econômica. (CAPRA,1997).
\end{abstract}

Nesse sentido, outro autor que defende a perspectiva holística Edgar Morin admite que o estudo da compreensão humana e da civilização é que revelará os caminhos para o 
autoconhecimento e somente a partir desse conhecimento de só próprio o homem terá a perspectiva de retomada do ponto de mutação. É preciso compreender a complexidade humana, evitar o egocentrismo, a pobreza ligada à desigualdade e a falta de solidariedade. É o caminho para a paz".

O texto de Edgar Morin, celebrizado atualmente como o porta voz da educação do futuro "Os Sete Saberes Necessários à Educação do Futuro 'nasceram de uma solicitação da ONU Organização das Nações Unidas acerca dos temas que não poderiam faltar para formar o cidadão do século 21. Essa lista segundo Morin começa com o estudo do próprio conhecimento. O segundo ponto é a pertinência dos conteúdos, para que levem a "apreender problemas globais e fundamentais". Em seguida vem o estudo da condição humana, entendida como unidade complexa da natureza dos indivíduos.

Ensinar a identidade terrena é o quarto ponto e refere-se a abordar as relações humanas de um ponto de vista global. O tópico seguinte é enfrentar as incertezas com base nos aportes recentes das ciências. O aprendizado da compreensão, sexto item, pede uma reforma de mentalidades para superar males como o racismo. Finalmente, uma ética global, baseada na consciência do ser humano como indivíduo e parte da sociedade e da espécie.

Assim, a reforma do conhecimento político e social e formação de uma ética pessoal, civil, humana planetária também é ressaltada por Edgar Morin como parte dessa reforma do conhecimento que salvará o professor do estresse, salvará os alunos de uma educação medíocre e salvará a humanidade de sí mesma. Outro precursor dessa área, Daniel Goleman (1998) afirma que "No mundo atual, não basta ser inteligente, esperto e preparado para competir. É preciso ter calma e empatia e persistir diante das frustrações para conseguir viver bem no amor, ser feliz com a família e vencer no mercado de trabalho."

Ao defender uma inteligência emocional, Goleman defende que pessoas que são emocionalmente adaptadas, que sabem conciliar seus sentimentos com a realidade e conseguem ler as emoções das outras, destacam-se em qualquer aspecto da vida, seja na intimidade das relações afetivas ou da interpretação das regras não escritas que governam o sucesso nas organizações e na vida. Assim, o autoconhecimento é chave fundamental para o desenvolvimento desse tipo de inteligência. Ressalta que é dotado de Inteligência Emocional quem é capaz de:

a) Automotivar-se e persistir diante de derrotas e frustrações.

b) Controlar impulsos, adiar a sua satisfação e impedir que o mau humor ou a preocupação se tornem sufocantes a ponto de comprometer a sua capacidade de raciocínio.

c) Não viver obcecado por suas próprias ideias. 
d) Ouvir o outro, lidar bem com suas emoções e ver a vida com otimismo.." (GOLEMAM,1998).

Ainda para esse autor o que diferencia as pessoas que chegam no topo das que ficam na média, quando elas têm as mesmas habilidades é a capacidade de resistir a uma rotina de treinamento árdua durante anos a fio, com calma, otimismo e esperança. Não existe experiência psicológica mais importante do que resistir a um impulso de raiva, mantendo a calma. Ela é a raiz do autoconhecimento e do contato apropriado com as emoções, uma vez que qualquer emoção leva ao impulso de agir.

Para que essas práticas resolutivas aconteçam Goleman (1998)sugere uma troca de ações e esforços: substituir o controle descendente (de cima para baixo, aquele responsável pela atenção ativa, e controle executivo das ações), por atividades mais passivas no modo ascendente (de baixo para cima, que não exigem esforço cognitivo), como uma pausa relaxante num ambiente tranquilo. Olhar paisagens naturais, caminhar em meio à natureza, assistir filmes, ou simplesmente respirar, constituem alguns bons exemplos também destaca o relevante papel que a autoconsciência desempenha em nossa vida, que traz consigo a atenção executiva.

Assim, nas palavras de CODO (2006) trabalho é uma dupla relação de transformação entre o homem e a natureza. O homem transforma a natureza e é transformado por ela. O homem torna-se parecido com a natureza e a natureza torna-se parecida com o homem. Mas, não é uma dupla transformação qualquer. É uma dupla relação de transformação entre homem e a natureza, geradora de significado. Trabalho é trabalho quando muda a natureza e quando gera significado.

\section{CONSIDERAÇÕES FINAIS}

A compreensão humana é o caminho para a paz. Para a educação do futuro, é preciso ensinar civilização, solidariedade e responsabilidade, que caminham juntas no mundo atual, globalizado. E que para a educação ser completa e eficaz ela "tem que ser transformada, inovada e reinventada constantemente" para atender e se adequar a realidade social, cultural e política de cada geração ( Morin) Esse é o fazer do professor holístico, mas antes de tudo é a o fazer do ser humano que por natureza é holístico. Se perdeu no caminho, mas é na educação ao fazer e ser educação é que reside a possibilidade de retorno à sua essência.

Para que o professor holístico saia dos moldes filosóficos para a vida real além de toda a motivação intrínseca ao ser humano é preciso que haja as mudanças de paradigmas de 
concepção de mundo e de educação, para que o fazer metodológico caminhe junto com fazer filosófico e a educação holística saia da utopia.

Um simples resgate de momentos com a natureza, diariamente pode fazer toda diferença nesse panorama grave e ascendente que aqui foi traçado. Pois o trabalho nada mais é que a relação saudável do homem com seu meio e o estresse acontece quando essa relação se danifica. E trabalhar com prazer pode se tornar um ato holístico e as mudanças de paradigmas só podem ocorrer por meio de vivências, de experiências que nos coloquem frente a frente com os limites do paradigma atual. 


\section{REFERÊNCIAS}

CAPRA, Frijof- A teia da vida, ed. Pensamento- Cultrix Ltda, São Paulo, 1996.

CODO, Wanderley e SAMPAIO, José Jackson Coelho (orgs.). Sofrimento psíquico nas organizações: saúde mental e trabalho. Petrópolis: Vozes, 1995.

DRUCKER, Peter F. Administração de organizações sem fins lucrativos: Princípios e práticas. Tradução Nivaldo Montinglli Jr. São Paulo: Pioneira Thomson Learning, 2002.

FREITAS, C.E.S. Trabalho estranhado em professores do ensino particular em Salvador em um contexto neoliberal. Tese de Doutorado apresentada ao Departamento de Sociologia da Universidade de Brasília. Brasília: UnB, 2005.A, Gustavo Filipe Barbosa (Org.). Segurança e medicina do trabalho: legislação. 3. ed. rev. atual. ampl. São Paulo: Gen, 2013. 848 p.

GOLEMAN, Daniel. Inteligência emocional: a teoria revolucionária que redefine o que é ser inteligente. Rio de Janeiro: Objetiva, c1998.

IMBERNÓN, F. Formação docente e profissional: formar-se para a mudança e a incerteza. $4^{\mathrm{a} e d}$. SP: Cortez, 2004.

LIBÂNEO, José Carlos. Adeus professor, adeus professora? novas exigências educativas e profissão docente / José Carlos Libâneo. - 6. ed.- São Paulo: Cortez, 2002.

MATURANA, Humberto. (MAGRO, Cristina et alii, org.). A ontologia da realidade. Belo Horizonte: Ed. UFMG, 2002.

MATURANA, Humberto. (MAGRO, Cristina; PAREDES, Victor, org.). Cognição, ciência e vida cotidiana. Belo Horizonte: Ed. UFMG, 2001.

MATURANA, Humberto; VARELA, Francisco. A árvore do conhecimento. Campinas: Editorial Psy, 1995.

MATURANA, Humberto; VARELA, Francisco. De máquinas e seres vivos - autopoiese: a organização do vivo. 3.ed. Porto Alegre: Artes Médicas, 1997.

MORIN, Edgar. Introdução ao pensamento complexo. Instituto Piaget, Portugal, 1995.

NÓVOA, A. Formação de professores e profissão docente. In: A. Nóvoa (org.). Os professores e sua formação. Lisboa: Nova Enciclopédia, 1992. 
PIMENTA, S. G.; ANASTASIOU, L. das G. C. Docência no ensino superior. São Paulo: Editora Cortez, 2005.

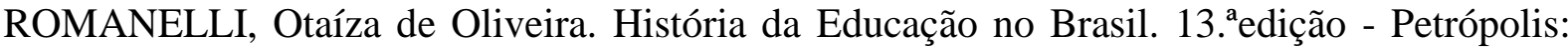
Vozes, 1991. 